\title{
PMCA2 via PSD-95 Controls Calcium Signaling by $\alpha 7$-Containing Nicotinic Acetylcholine Receptors on Aspiny Interneurons
}

\author{
David Gómez-Varela, ${ }^{1}$ Manuela Schmidt, ${ }^{2}$ Jeff Schoellerman, ${ }^{1}$ Eric C. Peters, ${ }^{3}$ and Darwin K. Berg ${ }^{1}$ \\ ${ }^{1}$ Division of Biological Sciences, University of California, San Diego, La Jolla, California 92093-0357, ${ }^{2}$ The Scripps Research Institute, La Jolla, California \\ 92037, and ${ }^{3}$ Genomics Institute of the Novartis Research Foundation, San Diego, California 92121
}

Local control of calcium concentration within neurons is critical for signaling and regulation of synaptic communication in neural circuits. How local control can be achieved in the absence of physical compartmentalization is poorly understood. Challenging examples are provided by nicotinic acetylcholine receptors that contain $\alpha 7$ nicotinic receptor subunits ( $\alpha 7$-nAChRs). These receptors are highly permeable to calcium and are concentrated on aspiny dendrites of interneurons, which lack obvious physical compartments for constraining calcium diffusion. Using functional proteomics on rat brain, we show that $\alpha 7$-nAChRs are associated with plasma membrane calcium-ATPase pump isoform 2 (PMCA2). Analysis of $\alpha 7$-nAChR function in hippocampal interneurons in culture shows that PMCA2 activity limits the duration of calcium elevations produced by the receptors. Unexpectedly, PMCA2 inhibition triggers rapid calciumdependent loss of $\alpha 7$-nAChR clusters. This extreme regulatory response is mediated by CaMKII, involves proteasome activity, depends on the second intracellular loop of $\alpha 7$-nAChR subunits, and is specific in that it does not alter two other classes of calcium-permeable ionotropic receptors on the same neurons. A critical link is provided by the scaffold protein PSD-95 (postsynaptic density-95), which is associated with $\alpha 7$-nAChRs and constrains their mobility as revealed by single-particle tracking on neurons. The PSD-95 link is required for PMCA2-mediated removal of $\alpha 7$-nAChR clusters. This three-component combination of PMCA2, PSD-95, and $\alpha 7$-nAChR offers a novel mechanism for tight control of calcium dynamics in neurons.

\section{Introduction}

Calcium is a key regulator of numerous biological processes in neurons. To achieve specificity, cells must tightly control the amount, time course, and spatial distribution of calcium elevations. A common strategy is to confine calcium influx to critical sites by means of protein-protein interactions that severely restrict the location of channels mediating the flux, as in the case of voltage-gated calcium channels at presynaptic terminals (Kaeser et al., 2011). Physical compartmentalization of the incoming calcium offers another mechanism, as seen for dendritic spines where intracellular diffusion is limited by the narrow spine neck

Received Nov. 30, 2011; revised March 7, 2012; accepted March 11, 2012.

Author contributions: D.G.-V., M.S., E.C.P., and D.K.B. designed research; D.G.-V., M.S., J.S., and E.C.P. performed research; D.G.-V. and M.S. contributed unpublished reagents/analytic tools; D.G.-V., M.S., E.C.P., and D.K.B. analyzed data; D.G.-V. and D.K.B. wrote the paper.

Grant support was provided by the National Institutes of Health (NS012601 and NS034569) and the TobaccoRelated Disease Research Program (17FT-0053 and 19XT-0072). D.G.V. is a Fundación para la Investigación Cientifica y Técnica postdoctoral fellow and a Tobacco-Related Disease Research Program postdoctoral fellow. We thank Jian Xu and S. Heinemann for providing the CD4- $\alpha 7$ and CD4- $\alpha 4$ chimeras and the $\alpha 7$-nAChR-GFP construct. We thank Xiao-Yun Wang for expert technical assistance, and Nicholas C. Spitzer and Paul A. Slesinger for comments on the manuscript.

The authors declare no competing financial interests.

D. Gómez-Varela's and M. Schmidt's present address: Max Planck Institute of Experimental Medicine, 37075 Göttingen, Germany.

Correspondence should be addressed to David Gómez-Varela, Division of Biological Sciences, University of California, San Diego, 9500 Gilman Drive, La Jolla, CA 92093-0357. E-mail: dgomezvarela@ucsd.edu.

DOI:10.1523/JNEUROSCI.5972-11.2012

Copyright $\odot 2012$ the authors $\quad 0270-6474 / 12 / 326894-12 \$ 15.00 / 0$
(Yuste, 2011). A third strategy is to impose multiple channelopening conditions that limit activation to special physiological circumstances. This is the case for calcium-permeable NMDA receptors, which, for activation, require membrane depolarization, the agonist glutamate, and a coagonist (Dingledine et al., 1999). These strategies can be combined, as exemplified by NMDA receptors constrained at postsynaptic sites on spines (Schiller et al., 1998; Yuste et al., 1999).

Apparently unconstrained by such strategies are homopentameric $\alpha 7$-containing nicotinic acetylcholine receptors ( $\alpha 7$-nAChRs). These are widely expressed but are not confined to compartments, such as spines, though the receptors have a high relative calcium permeability (Bertrand et al., 1993; Séguéla et al., 1993) and regulate calcium-dependent events (Jones et al., 1999; Dajas-Bailador and Wonnacott, 2004; Dickinson et al., 2007; Albuquerque et al., 2009; Miwa et al., 2011). Further, they require only the agonist acetylcholine for activation and may even participate in "volume transmission," responding to transmitter diffusely distributed (Descarries et al., 1997). Most challenging are the relatively high numbers of $\alpha 7$ nAChRs found on dendritic shafts of hippocampal aspiny interneurons (Khiroug et al., 2003; Fayuk and Yakel, 2007), where the receptors have been reported to participate in synaptic plasticity (Rózsa et al., 2008). Because interneurons display several forms of pathway-specific synaptic plasticity (Kullmann and Lamsa, 2007), they must carefully regulate local calcium dynamics. How can substantial calcium influx, as mediated by $\alpha 7-n A C h R s$, be permitted and yet controlled in such cases? 
Performing functional proteomics, we show here that $\alpha 7$ nAChRs are functionally linked to the plasma membrane calcium-ATPase pump isoform 2 (PMCA2) on interneurons via the scaffold protein PSD-95 (postsynaptic density-95). PMCA2 controls the extrusion of calcium upon $\alpha 7$-nAChR activation. Remarkably, blockade of PMCA2s, by rapidly decreasing the number of $\alpha 7$-nAChR clusters on the cell surface, causes a substantial decrease in the magnitude of $\alpha 7$-nAChR-dependent calcium transients. This decrease does not occur if PSD-95 levels are reduced by RNA interference (RNAi). Single-particle tracking (SPT) studies using quantum dots (QDs) indicate that PSD-95 constrains $\alpha 7$-nAChR movements on the cell surface, placing the receptors under PMCA2 control. If pump activity is compromised, the PSD-95 link enables the cell to reduce the number of $\alpha 7$-nAChR clusters.

\section{Materials and Methods}

Isolation of $\alpha 7-n A C h R$ complexes from rat brain. Ten postnatal day 9 (P9) rat brains of either sex were homogenized ( $10 \mathrm{~s}$ driller pulse on ice) with ice-cold solubilization buffer ( $\mathrm{SB} ; 4 \mathrm{ml} / \mathrm{g}$ brain tissue; $5 \mathrm{~g}$ total) containing (in mM): 150 Tris- $\mathrm{HCl}, \mathrm{pH} 8 ; 100 \mathrm{NaCl}$; 0.5 EDTA; and glycerol $10 \%$. After centrifuging at $3800 \mathrm{rpm}$ for $8 \mathrm{~min}$ at $4^{\circ} \mathrm{C}$, the supernatant fraction was collected and saved on ice; the pellet was suspended in ice-cold SB $(1.3 \mathrm{ml} / \mathrm{g}$ brain tissue) and centrifuged again at $3800 \mathrm{rpm}$ for $8 \mathrm{~min}$ at $4^{\circ} \mathrm{C}$. The two supernatant fractions were pooled and centrifuged at $45,000 \mathrm{rpm}$ for $40 \mathrm{~min}$ at $4^{\circ} \mathrm{C}$. The resulting pellet fraction was resuspended in ice-cold SB containing $0.5 \%$ sodium-deoxycholate and $0.5 \%$ Nonidet P-40 (NP-40; $500 \mu \mathrm{l} / \mathrm{g}$ brain tissue) and homogenized by 20 strokes with a P1000 micropipette, followed by 20 strokes with a P200 micropipette. The resulting suspension was incubated $2 \mathrm{~h}$ at $4^{\circ} \mathrm{C}$ on a horizontal shaker at $210 \mathrm{rpm}$ and then centrifuged at 45,000 rpm for 40 $\min$ at $4^{\circ} \mathrm{C}$. The resulting supernatant fraction $(500 \mu \mathrm{l})$ was incubated with $40 \mu \mathrm{l}$ of $\alpha$-bungarotoxin (Bgtx) beads overnight at $4^{\circ} \mathrm{C}$ with gentle rotation. Bgtx beads were prepared by coupling $\alpha$-bungarotoxin (Invitrogen) to Actigel ALD (Sterogene Bioseparation) using the manufacturer's protocol. Negative controls included either substitution of unconjugated beads for the Bgtx beads or addition of $1 \mathrm{~mm}$ nicotine to the solution before applying to the Bgtx beads. The beads were then collected by centrifugation at $5000 \mathrm{rpm}$ for $1 \mathrm{~min}$ and washed six times by gentle rotation for $10 \mathrm{~min}$ at $4^{\circ} \mathrm{C}$ with $1 \mathrm{ml}$ aliquots of ice-cold SB containing $150 \mathrm{~mm} \mathrm{NaCl}$ plus $0.5 \%$ sodium deoxycholate and $0.5 \% \mathrm{NP}-40$ before recentrifugation. Absorbed proteins were then eluted by incubating 10 min at $75^{\circ} \mathrm{C}$ in $40 \mu \mathrm{l}$ of elution buffer containing: $1 \times$ lithium dodecyl sulfate sample buffer (Thermo Scientific) and $1 \times$ NuPAGE sample reducing agent (Invitrogen). The resulting mixtures were resolved by onedimensional SDS-PAGE, and each resolved lane was cut into 16 equal gel slices, which were analyzed separately by mass spectrometry.

Mass spectrometry. Excised gel bands were subjected to in-gel digestion using a Micromass MassPREP Station in conjunction with the manufacturer-specified protocols. Briefly, gel pieces were rinsed $(2 \times$ with $50 \%$ acetonitrile/50 $\mathrm{mm}$ ammonium bicarbonate), dehydrated (acetonitrile), reduced (dichloro-diphenyl-trichloroethane), alkylated (iodoacetamide), and digested with sequencing grade trypsin overnight. The resulting peptides were extracted with $30 \mu \mathrm{l}$ of $1 \%$ formic acid. Automated nanoscale liquid chromatography-tandem mass spectrometry was performed using a ThermoFinnigan Surveyor HPLC and LTQ Orbitrap ion trap mass spectrometer along with a variation of the "vented column" approach. Ten microliters of a tryptic digest extract was loaded onto a $5 \mathrm{~cm}$ long $\times 75 \mu \mathrm{m}$ inner diameter precolumn packed with $5 \mu \mathrm{m}$ C-18 silica (Monitor $100 \AA$ ) retained by a Kaisel frit. After thorough washing, the vent was closed and, by starting the reversed-phase run, the sample was transferred to a $12 \mathrm{~cm}$ long $\times 75 \mu \mathrm{m}$ inner diameter column with a pulled $5 \mu \mathrm{m}$ tip packed with the same material. The chromatographic profile was from $100 \%$ solvent A $(0.1 \%$ acetic acid) to $50 \%$ solvent B $(0.1 \%$ acetic acid in acetonitrile $)$ in $30 \mathrm{~min}$ at $\sim 200 \mathrm{nl} / \mathrm{min}$ (manual split from $300 \mu \mathrm{l} / \mathrm{min}$ ), and also allowed for appropriate times for column washing and reequilibration. An angiotensin 1 standard (1.25 pmol) was run between each sample to eliminate carryover as well as monitor overall system performance. The LTQ Orbitrap acquisition method involved one mass spectrometry (MS) precursor ion scan followed by five data-dependent tandem MS scans. Dynamic exclusion was enabled for a repeat count of $1 \mathrm{~s}$, repeat duration of $15 \mathrm{~s}$, and exclusion duration of $30 \mathrm{~s}$.

Database search. Tandem MS data were used to search a rat-specific database with an appended reverse sequence copy (EBI-IPI_rat_3.36 database, 82,502 entries) using Sequest (version 3.0; ThermoFinnigan). Searches were performed allowing for the fixed modification of cysteine (carbaminomethyl), the variable modifications of Met (oxidation), and no enzyme specificity. Scaffold (version Scaffold_3_00_02; Proteome Software) was used to validate tandem MS-based peptide and protein identifications. Peptide identifications were accepted if they could be established at $>95.0 \%$ probability as specified by the Peptide Prophet algorithm (Keller et al., 2002). Protein identifications were accepted if they could be established at $>99.9 \%$ probability and contained at least two identified peptides. Protein probabilities were assigned by the Protein Prophet algorithm (Nesvizhskii et al., 2003).

DNA constructs. Mouse PMCA2 (clone 30621322, Openbiosystems) was extracted from the pYX-Asc vector using appropriate oligonucleotides to ligate the PMCA2 cDNA between the EcoR1/XhoI sites of the multiple cloning site of pcDNA 3.1/Myc-His vector (Invitrogen). The point mutations in the PDZ (PSD-95/Discs large/zona occludens-1) domains of the CD4- $\alpha 7$ loop were made using the QuikChange Lightning Site-Directed Mutagenesis kit (Agilent Technologies). The primer pairs to change both PDZ domains were the same as described previously (Baer et al., 2007). All constructs were verified by sequencing. Silencing of rat PMCA2 was done by using a SureSilencing short hairpin RNA (shRNA) plasmid (catalog number KR52851G). SAP-102-XFP (synapse associated protein-102-XFP), sh95-XFP, and shScr95-XFP were generated as previously described (Conroy et al., 2003; Neff et al., 2009).

HEK293 transfections. HEK293 (human embryonic kidney 293) cells were transferred from a $75 \mathrm{~cm}^{2}$ bottle at confluency to $10 \mathrm{~cm}$ plates (Corning) at a 1:9 dilution. Cells were transfected by adding $1 \mathrm{ml} /$ plate of HEK293 medium (Opti-MEM, Invitrogen) with $20 \mu \mathrm{l}$ of Fugene/plate (Promega) with either $4 \mu \mathrm{g}$ of PMCA2-Myc and $8 \mu \mathrm{g}$ of $\alpha 7$-GFP or $8 \mu \mathrm{g}$ of CD4 construct. After $3 \mathrm{~d}$, cells were detached from the plates by pipetting PBS buffer and collected by centrifuging at 10,000 rpm for $5 \mathrm{~min}$ at room temperature. The cells were lysed by adding lysis buffer (in mM): 0.5 EDTA, $100 \mathrm{NaCl}, 10 \%$ glycerol, $1 \%$ dodecyl-D-maltoside, 50 Tris$\mathrm{Hcl}$, and 1 protease inhibitors, $\mathrm{pH} 7.5$, and passing through 20 and 25 gauge syringes. After $30-60 \mathrm{~min}$ incubation on ice, the lysate was centrifuged $10 \mathrm{~min}$ at $10,000 \mathrm{rpm}$ at $4^{\circ} \mathrm{C}$ to remove insoluble material. Antibodies (Abs) conjugated to beads and recognizing Myc (clone 9E11, Santa Cruz Biotechnology), GFP (A11122, Invitrogen), or CD4 (MEM241, Santa Cruz Biotechnology) were incubated with the supernatant fraction overnight at $4^{\circ} \mathrm{C}$ with gentle rotation to bind the corresponding antigen. After three washes with diluted lysis buffer (1:1 dilution), bound proteins were eluted with elution buffer (see above), separated by SDSPAGE, and transferred to nitrocellulose membranes.

Western blots. For material from transfected HEK293 cells, Western blots were probed with anti-Myc Ab (1:500; clone 9E11, Santa Cruz Biotechnology) or anti- $\alpha 7$-nAChR Ab (1:500; C-20, Santa Cruz Biotechnology), followed by HRP-conjugated secondary Ab (1:2000; Jackson Laboratories). For material from rat brain extracts, the blots were probed with anti-PSD-95 Ab (1:1000; Cell Signaling Technology) or anti- $\alpha 7$ nAChR Ab (1:1000; 1:500; C-20, Santa Cruz Biotechnology) followed by HRP-conjugated secondaries. Antibody binding was detected with ECL reagents (Pierce) and developed with Kodak X-OMAT Blue XB Film.

Hippocampal cultures. Hippocampal cultures were prepared from 18d-old to 19-d-old Sprague Dawley rat embryos as previously described (Kawai et al., 2002). Briefly, hippocampi were removed rapidly under stereomicroscopic observation, cut into small pieces, and digested with $20 \mathrm{U} / \mathrm{ml}$ of trypsin (Invitrogen;) in HBSS Invitrogen) at $37^{\circ} \mathrm{C}$ for $12 \mathrm{~min}$. The tissue segments were then transferred to Neurobasal medium (Invitrogen) with $10 \%$ heat-inactivated horse serum (Invitrogen), triturated with a fire-polished Pasteur pipette, and plated at $1 \times 10^{5}$ cells per $12 \mathrm{~mm}$ glass coverslip previously coated with poly-D-lysine ( $>300 \mathrm{kDa}$; Sigma). 
A

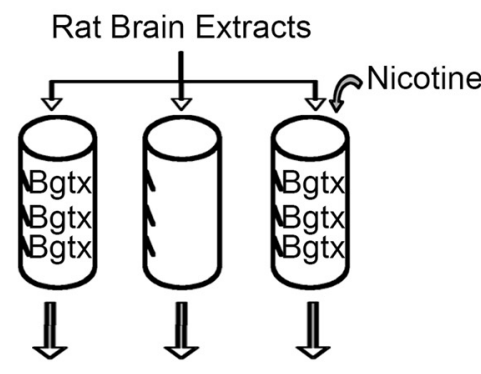

Blot: anti $\alpha 7-n A C h R$ Ab

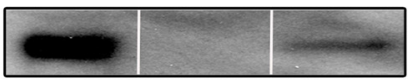

C

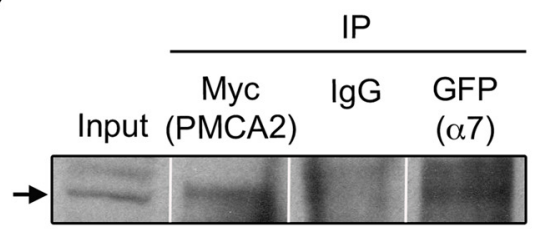

Blot: PMCA2 Ab

\begin{tabular}{|ccc|}
\cline { 2 - 3 } $\begin{array}{c}\text { Myc } \\
\text { Input (PMCA2) }\end{array}$ & IgG & GFP \\
& $(\alpha 7)$ \\
\hline 0 & & \\
\hline
\end{tabular}

Blot: $\alpha 7-n A C h R$ Ab
B

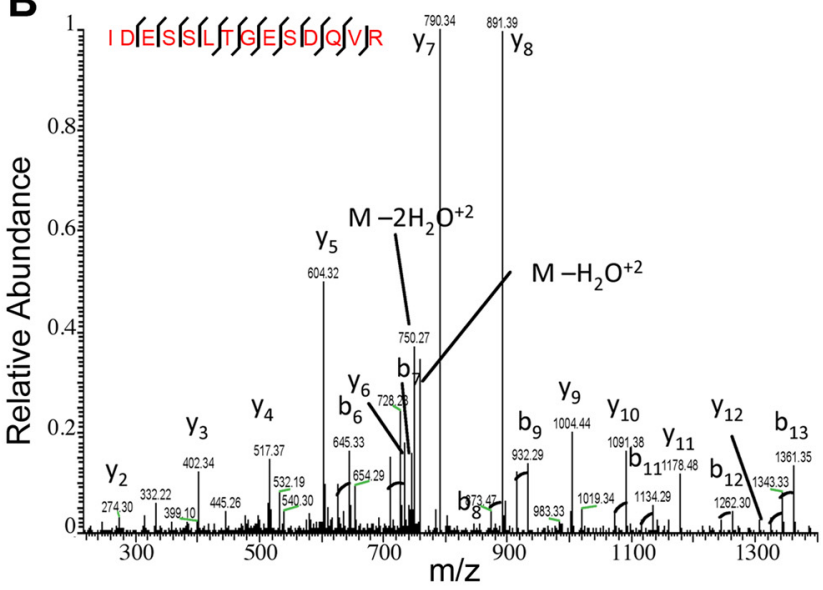

D
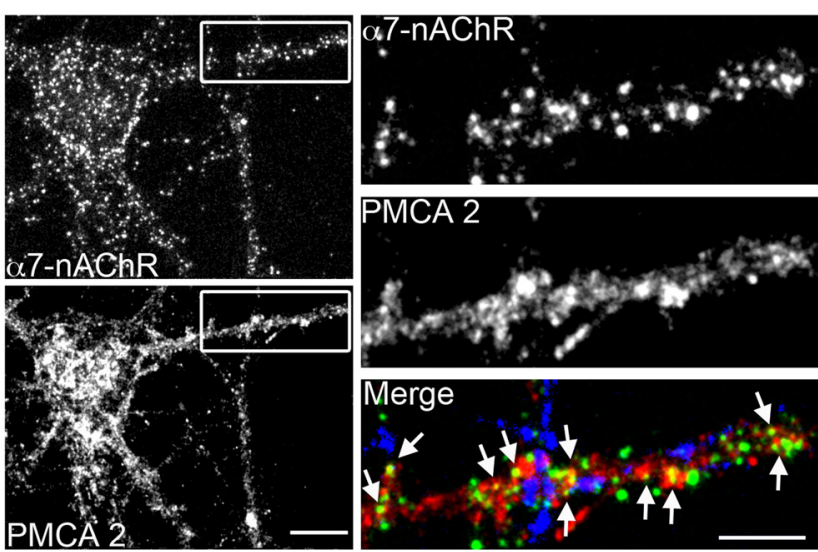

Figure 1. Proteomic analysis reveals PMCA2 associated with $\alpha 7$-nAChRs. $A$, Rat brain extracts were passed through affinity columns containing Bgtx coupled to actigel beads (left), beads alone (middle), or Bgtx beads incubated with nicotine to block specific $\alpha$ 7-nAChR binding (right). The specificity of the procedure was confirmed by eluting bound material followed by Western blot probed with anti- $\alpha$ 7-nAChR $\mathrm{Ab}$, which identified receptor prominently in the Bgtx bead lane. $\boldsymbol{B}$, Tandem MS spectra of a peptide unique for PMCA2. The fragment $^{+}$-ion and $\mathrm{b}^{+}$-ion series are indicated together with the amino acid sequence derived from the mass differences (red). C, Coimmunoprecipitation of PMCA2 and $\alpha 7$-nAChRs transiently transfected into HEK293 cells. Proteins were immunopurified (IP) with Abs against PMCA2Myc (Myc), nonspecific Abs (IgG), or against $\alpha$-nAChR-GFP (GFP). Arrow indicates the PMCA-Myc band. Similar results were obtained from three independent experiments. $\boldsymbol{D}$, Hippocampal interneurons identified by GAD65 staining (Merge, blue; 15-17 d in vitro) were stained for surface $\alpha 7$-nAChRs (green) and PMCA2 (red). Magnified images show colocalization of $\alpha 7$-nAChRs and PMCA2 (Merge, arrows indicate examples). Scale bars: (in PMCA2) left columns, $10 \mu \mathrm{m}$; (in Merge) right columns, $5 \mu \mathrm{m}$.

Subsequent feeding occurred twice weekly, each time replacing half the volume with fresh Neurobasal media with 2\% B-27 (Invitrogen). The cultures were maintained in a humidified tissue culture incubator with $5 \% \mathrm{CO}_{2}$ and taken for use after 15-17 d. Cultures were transfected using the calcium-phosphate method (Clontech; Goetze et al., 2004) on days 7-8.

Immunocytochemistry. For immunostaining, hippocampal neurons in culture were incubated with the indicated compounds (e.g., CX3A, $250 \mu \mathrm{M}$, for $1 \mathrm{~h}$ at $37^{\circ} \mathrm{C}$ in hippocampal culture medium) (see above). After three washes with warm culture medium, surface $\alpha 7$-nAChRs were labeled by incubating with Bgtx-Alexa488 (100 nM; Invitrogen) for $30 \mathrm{~min}$ at $37^{\circ} \mathrm{C}$. After two washes with HEPES buffer, cells were fixed with 2\% PFA in PBS for $10 \mathrm{~min}$ at room temperature, and then permeabilized by incubating $10 \mathrm{~min}$ with $0.1 \%$ Triton X-100 in PBS. To label PMCA2, cells were incubated with an anti-PMCA2 Ab (PA1-915, Pierce) for $1 \mathrm{~h}$ at room temperature in PBS containing 5\% normal donkey serum. PSD-95 and GAD-65 labeling were obtained with anti-PSD-95 Ab (MA1-046, Pierce) and anti-GAD-65 Ab (either GAD-6 antibody from the Hybridoma Bank or AB1511 from Millipore. The GAD- 6 antibody developed by Gottlieb was obtained from the Developmental Studies Hybridoma Bank, which was established under the auspices of the National Institute of Child Health and Human Development and is maintained by the University of Iowa, Department of Biology, Iowa City, Iowa), respectively. After washing three times in PBS, cells were incubated with appropriate donkey FITC, Cy3-conjugated secondary Ab, or
Cy5-conjugated secondary $\mathrm{Ab} 2 \mathrm{~h}$ at room temperature (1:250; Jackson ImmunoResearch Laboratories), washed three times with PBS, and mounted on slides for imaging.

Confocal images were acquired in sequential mode using a Leica SP5 confocal microscope with settings that did not saturate the fluorescence signals and that fulfilled Nyquist sampling criteria. ImageJ software was used for quantifying the number of specific protein clusters. Four regions of interest (ROIs) of $20 \mu \mathrm{m}$ in length were randomly selected per field of view along the dendrites of interneurons, identified by GAD- 65 staining. ROIs were binarized automatically using the mean of the background value inside the dendrite plus $3 \times$ the $S D$ as an intensity threshold value for defining a cluster or puncta in each image. Clusters (puncta) within an ROI were counted if they had at least $3 \times 3$ pixels above threshold (pixel diameter, $80 \mathrm{~nm}$ ). Data are expressed as the mean plus SEM per dendritic length of $20 \mu \mathrm{m}$ and represent at least six images from each of three or more cultures.

Calcium imaging. Hippocampal neurons in culture were incubated with $5 \mu \mathrm{M}$ of Fluo-4 (Invitrogen) for $30 \mathrm{~min}$ at room temperature in recording medium containing (in $\mathrm{mm}$ ): $160 \mathrm{NaCl}, 10$ HEPES, 10 glucose, $4.5 \mathrm{KCl}, 2 \mathrm{CaCl}_{2}, 1 \mathrm{MgCl}_{2}$, $\mathrm{pH}$ 7.4. Residual dye was removed with three washes using recording medium, and the neurons were incubated an additional $30 \mathrm{~min}$ at $37^{\circ} \mathrm{C}$ to allow equilibration. The neurons were then placed in a recording chamber on the SP5 Leica confocal stage and calcium fluorescence images were obtained at a frequency of $9 \mathrm{~Hz}$ using a 
A
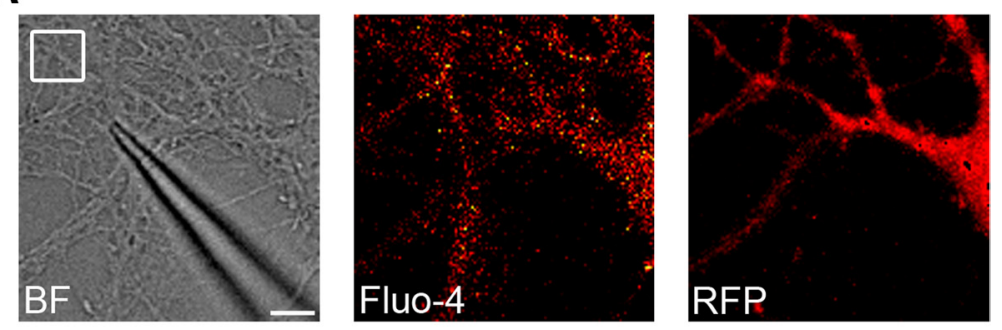

B

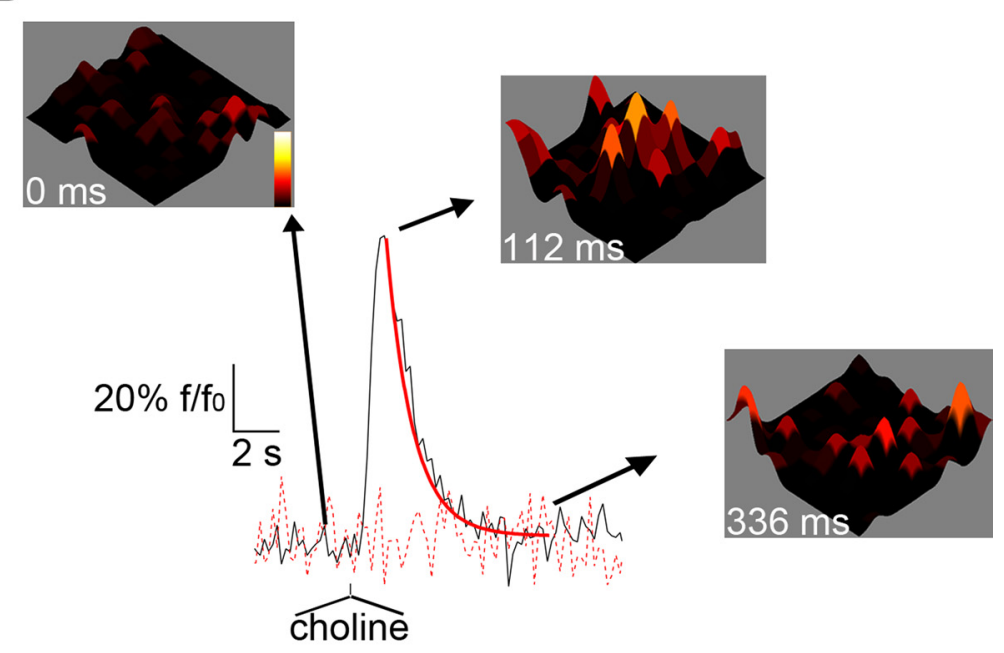

C Decay Rate

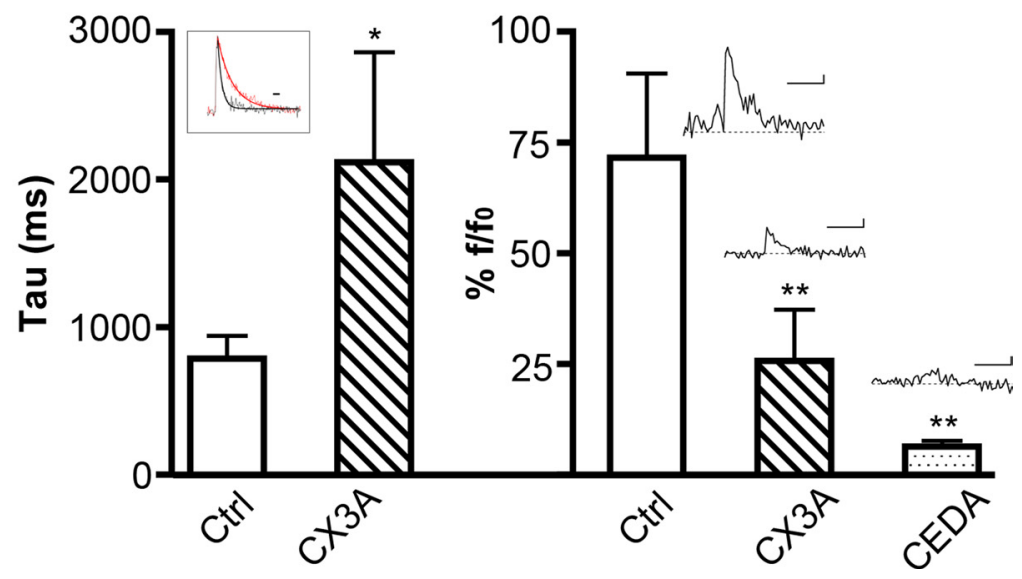

Figure 2. PMCA2 is functionally linked to $\alpha 7$-nAChRs. A, Position of the pipette (bright field, BF, left) and basal Fluo-4 fluorescence levels (Fluo-4, middle) on an aspiny neuron transfected with RFP (right) to control for cell volume change artifacts. BF, Inset, Area receiving focal application of choline. Scale bar: $5 \mu \mathrm{m}$. B , Choline application activates $\alpha 7$-nAChRs, producing a transient calcium elevation. Images show 3D representation of relative calcium levels in a microdomain before ( $0 \mathrm{~ms}$ ) and after (112 and 336 ms) choline application. The decay phase of the response was fit with a single exponential (red). C, Left, PMCA2 blockade by CX3A slows the decay phase of calcium elevation induced by $\alpha 7$-nAChR activation. Insert shows the comparison of decay kinetics for $\alpha 7$-nAChR-dependent calcium transients in control (black) and CX3A (red), normalized for peak amplitude (790 \pm 152 and $2130 \pm 754 \mathrm{~ms}$, respectively; ${ }^{*} p=0.033$ by two-tailed $t$ test; $n=10-12$ interneurons). Scale bar: $2 \mathrm{~s}$. Right, Peak calcium responses induced by $\alpha 7$-nAChR activation in vehicle (Ctrl) versus the PMCA2 inhibitors CX3A and carboxyeosin (CEDA). Inserts show representative traces for the responses $\left(71.5 \pm 19,21.7 \pm 11.5\right.$, and $6.3 \pm 1.3 \%$, respectively; ${ }^{* *} p=0.002$ by one-way ANOVA with post hoc Bonferroni test; $n=10-12$ interneurons). Scale bars: vertical, $20 \%$; horizontal, $2 \mathrm{~s}$.

$63 \times$ (numerical aperture, 0.9 ) water immersion objective. A brief (50 $\mathrm{ms}$ ) puff of $1 \mathrm{~m}$ choline was delivered locally at 2 psi using a micropipette with $1 \mu \mathrm{m}$ tip diameter placed $5 \mu \mathrm{m}$ from the dendritic surface (Fayuk and Yakel, 2007). Increments in fluorescence $(f)$ were normalized to the average baseline fluorescence $\left(f_{0}\right)$ measured during a $1 \mathrm{~min}$ period immediately before the application of choline. Recordings were obtained from at least three cultures and at least four neurons per culture. Data are expressed as the mean \pm SEM unless otherwise indicated.

Single-particle tracking. QDs (Invitrogen) tethered to individual $\alpha 7$-nAChRs via specific biotinylated ligands were used as fluorescent probes to follow the mobility of nAChRs. Synapses were labeled using MitoTracker 580 staining (100 nM, Invitrogen). MitoTracker Red 580 staining was performed by adding the reagent to the culture medium for $2 \mathrm{~min}$ at $37^{\circ} \mathrm{C}$ and washing two times with culture media. After rinsing three times with PBS containing $0.1 \% \mathrm{BSA}$, neurons were incubated with biotinylated Bgtx (Biot-Bgts, $10 \mathrm{~nm}$, Invitrogen) for $10 \mathrm{~min}$ on ice, washed three times with PBS plus $0.1 \%$ BSA, and then incubated for 5 min with $0.5 \mathrm{~nm}$ streptavidin-coated QDs (605 $\mathrm{nm})$ on ice. Cultures were washed three times with recording medium containing (in $\mathrm{mm}$ ): $160 \mathrm{NaCl}, 10 \mathrm{HEPES}, 10$ glucose, $4.5 \mathrm{KCl}, 2$ $\mathrm{CaCl}_{2}, 1 \mathrm{MgCl}_{2}, \mathrm{pH}$ 7.4. Negative controls used streptavidin-QDs alone or used $100 \mu \mathrm{M}$ nicotine to compete with the Biot-Bgtx. To minimize tracking of internalized QD-nAChRs, all movies were confined to a $20 \mathrm{~min}$ period immediately after labeling (Charrier et al., 2006). Treating cells with an acid wash (30 s, pH 5.5, at room temperature; Ehlers et al., 2007) removed the vast majority of QDs, confirming that little, if any, internalization had occurred.

Neurons were imaged with an inverted microscope (Zeiss Axiovert 200M) equipped with a $63 \times$ oil immersion objective (numerical aperture, 1.40). Samples were illuminated with a mercury lamp and imaged with appropriate excitation filters, dichroic mirrors, and emission filters. Settings were HQ545/30, Q565LP, and HQ610/75M, respectively for MitoTracker; D420/40X, 470DCXR, and D605/40, respectively, for QD 605; and HQ487/25, Q505LP, and HQ535/40M, respectively, for GFP. Fluorescence images were acquired with $95 \mathrm{~ms}$ exposure times at $10 \mathrm{~Hz}$ using a CCD camera (AxioCam MRm, Zeiss) and AxioVision 4.6 software (Zeiss).

Single QDs were identified by their characteristic blinking and were tracked with ImageJ (National Institutes of Health) plug-in SpotTracker, after processing image sequences with the SpotEnhancing Filter plug-in (Sage et al., 2005). QD trajectories were sorted into synaptic and extrasynaptic bins. Synapses were identified as boutons staining positive with the mitochondria marker MitoTracker; a punctate region of three pixels in diameter $(0.2 \mu \mathrm{m} /$ pixel) within the labeled space was used to assess QD movement at that synaptic site (Aravanis et al., 2003). QD trajectories were retained only if they contained at least 10 consecutive frames with the center of the QD remaining within the space (synaptic or extrasynaptic) throughout. Frames in which the fluorescence signal disappeared due to blinking of the QD were omitted from the analysis. In such cases, the trajectory was reconstructed by joining trajectory fragments immediately before and after the blink. Instantaneous diffusion coefficients $\left(D_{\mathrm{i}}\right)$ were determined for each trajectory as described previously (Gómez-Varela et al., 2010), fitting the first five points of the mean squared displacement 
(MSD) curve versus the lag time. The global localization accuracy was determined by testing the vibrational stability of the setup and calculating MSD for immobile spots. Immobile QDs were defined as streptavidin-QDs stationary on the surface of glass-bottom dishes in the absence of neurons. The localization accuracy was $50 \mathrm{~nm}$, and the resolution limit in terms of diffusion coefficients was 0.008 $\mu \mathrm{m}^{2} / \mathrm{s}$.

Feret's diameter was measured as the distance between the two most distal points of a trajectory.

\section{Results}

\section{Association of PMCA2}

\section{with $\alpha 7$-nAChRs}

To identify proteins associated with $\alpha 7$ nAChRs, we affinity-purified protein complexes from rat brain extracts using Bgtx beads. Negative controls included unlinked beads or inclusion of the competitor nicotine along with the Bgtx beads (Fig. 1A). Differentially bound proteins were identified by comparative liquid chromatography-tandem mass spectrometry analysis of the retained fractions. Importantly, one protein found only in the Bgtx bead eluate was PMCA2 (Fig. 1B). PMCA isoforms are members of a multigene family of highaffinity calcium pumps that are expressed in the brain and extrude calcium from the cytosol (Kozel et al., 1998; Strehler and Zacharias, 2001; Jensen et al., 2007; Strehler et al., 2007). The bait protein $\alpha 7-\mathrm{nAChR}$ was also found only in the Bgtx bead eluate (data not shown), validating the approach. We verified association of $\alpha 7-n A C h R s$ with PMCA2 by performing reciprocal coimmunoprecipitation of the two from HEK293 cells transiently transfected with Myc-tagged PMCA2 and GFP-tagged $\alpha 7$ nAChR (Fig. 1C). Further, immunostaining of hippocampal interneurons in cell culture revealed a considerable degree of colocalization of the two endogenous proteins (Fig. 1D). Together, the results strongly support a previously unrecognized association between $\alpha 7$-nAChRs and PMCA2.

\section{A functional link between $\alpha 7-n A C h R$ and PMCA2}

To test the effects of PMCA2 on $\alpha 7$-nAChR function, we loaded hippocampal neurons in culture with the calcium indicator Fluo-4 (Fig. $2 A$ ) and then focally activated $\alpha 7$-nAChRs by applying the specific agonist choline from a micropipette positioned $5 \mu \mathrm{m}$ from the dendrite (Fig. 2A). A brief application of choline to an interneuron elicited calcium transients with magnitude and kinetics (Fig. 2 B) comparable to those described previously using this technique (Fayuk and Yakel, 2007). These transients were not due to changes in cell volume (artifacts) caused by the choline puffs, as monitored by the distribution of soluble red fluorescent protein in the cell (Fig. $2 A, B$ ). A $1 \mathrm{~h}$ inhibition of PMCA2 activity by incubation with the peptide caloxin 3A (CX3A, $250 \mu \mathrm{M}$; Pande et

A
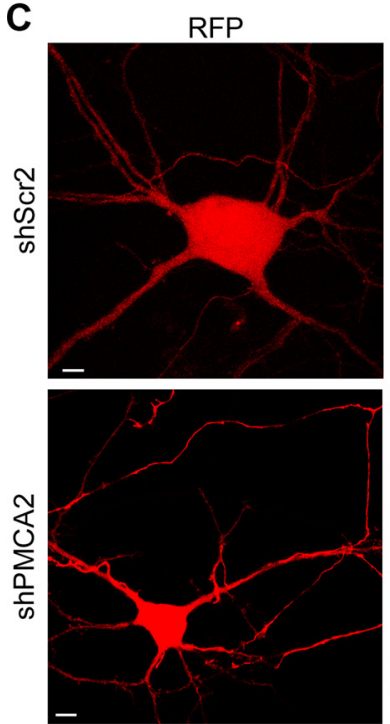

CX3A
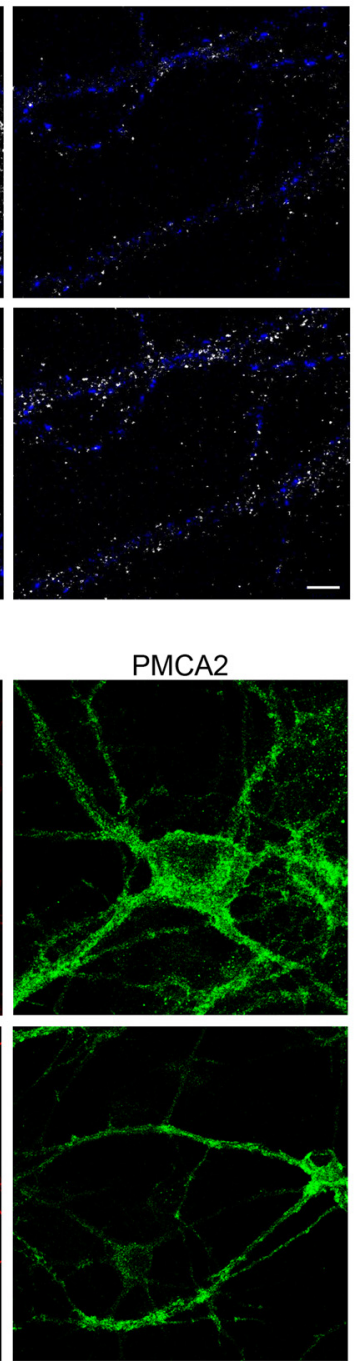

B

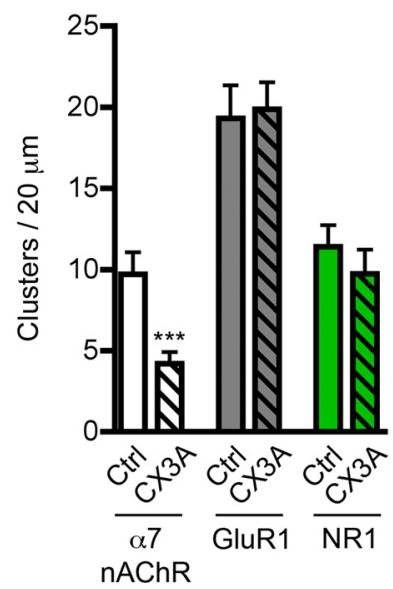

D

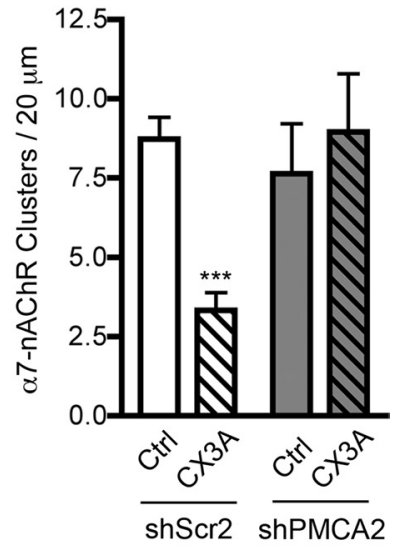

Figure 3. PMCA blockade decreases the number of $\alpha 7$-nAChR clusters on hippocampal interneurons. $A$, Images of $\alpha 7$-nAChR and GluR1 receptor clusters on the surface of the same interneurons (GAD65, blue) in either control (Ctrl) or CX3A. Scale bar: $10 \mu \mathrm{m}$. .5 for control and $\left(X 3 A\right.$, respectively; ${ }^{* * *} p=0.0009$ by two-tailed $t$ test; $n=15-23$ interneurons). $C$, Representative expression of PMCA2 (PMCA2, green) compared with neighbor neurons and to shScramble-transfected neurons (shScr2). Scale bars: Top, left, $5 \mu \mathrm{m}$; bottom, left, $10 \mu \mathrm{m}$. (D) PMCA-dependent reduction in $\alpha 7$-nAChR cluster number is cell-autonomous as demonstrated by the lack of CX3A effects when PMCA2 is knocked down by RNAi (shPMCA2/CX3A) but not by scrambled control (shScr2/CX3A). Values for shScr2 were $8.7 \pm 0.7$ and $3.3 \pm 0.6$ for control and $\mathrm{CX} 3 \mathrm{~A}$, respectively; and for shPMCA2:7.6 \pm 1.5 and $9 \pm 2.8$ for control and $C X 3 \mathrm{~A}$, respectively; ${ }^{* * *} p=0.0008$ by two-tailed $t$ test $; n=10-12$ interneurons.

al., 2005) significantly slowed calcium clearance following $\alpha 7$ $\mathrm{nAChR}$ activation; this is reflected in the exponential fit of the decay phase of the calcium transient (Fig. 2C). Notably, PMCA2 inhibition by CX3A also produced a substantial decrease in the peak magnitude of the calcium response (Fig. 2C). An even greater decrement was observed with carboxyeosin $(10 \mu \mathrm{M})$, another inhibitor of PMCA isoforms (Gatto et al., 1995; Fig. 2C). The results clearly suggest a functional association between PMCA2 and $\alpha 7$-nAChRs.

\section{Dependence of surface $\alpha 7-n A C h R s$ on PMCA2 activity}

The finding that PMCA2 inhibition reduced the magnitude of the rapid calcium transients generated by $\alpha 7$-nAChRs on interneurons raised the possibility that pump blockade might trigger re- 
ceptor loss. To test this, we inhibited PMCA2 activity with CX3A and then labeled surface $\alpha 7$-nAChRs with Bgtx conjugated to Alexa Fluor 488 (Zago et al., 2006; Fig. 3A). Inhibition of PMCA2 significantly reduced the number of $\alpha 7$-nAChR clusters on the interneuron surface (Fig. 3B). No change was seen in the number of clusters comprising GluR1-containing AMPA receptors (GluR1s), another calcium-permeable receptor expressed by the same interneurons (Fig. $3 A, B$ ). Nor was any change seen in NR1containing NMDA receptors (NR1s), a calcium-permeable receptor previously shown to be associated in part with PMCA2 in postsynaptic compartments (Garside et al., 2009). The results reveal a remarkable regulatory response of interneurons to control $\alpha 7$-nAChRs.

The physical association of PMCA2 with $\alpha 7$-nAChRs identified by proteomics and the proximity of the two proteins in the same dendrite shown by immunostaining suggested that the relevant PMCA2s mediating the loss of receptor clusters were on the same interneuron. The pump is known, however, to be distributed both presynaptically and postsynaptically (Jensen et al., 2007; Garside et al., 2009). We used RNAi to identify the relevant PMCA2 population. An shRNA construct for PMCA2 (shPMCA2) dramatically reduced the amount of PMCA2 in the dendrites of interneurons expressing the construct (Fig. $3 C$ ) and prevented CX3A treatment from affecting the number of $\alpha 7$ nAChR clusters on the same dendrite (Fig. 3D). A scrambled shRNA control (shScr2) had no effect (Fig. 3D). The results confirm the specificity of the CX3A effect as being mediated by PMCA2 and demonstrate that the relevant PMCA2s are those on the same cell as the $\alpha 7$-nAChRs being regulated.

\section{Mechanisms mediating the PMCA2 effect on $\alpha 7$-nAChRs}

To identify signaling cascades mediating the PMCA2 effects on $\alpha 7$-nAChR cluster number, we tested whether increases in intracellular calcium were involved. After loading the neurons with the intracellular calcium chelator BAPTA-AM, we found that inhibition of PMCA2 no longer decreased the number of receptor clusters (Fig. 4A). Further, inhibition of calcium, calmodulindependent protein kinase II (CaMKII) with the specific blocker KN-93 also abolished the PMCA2-dependent loss of receptor clusters, whereas the inactive analog KN-92 had no effect (Fig. $4 A$ ). To test whether the regulatory effect depended on protein degradation, we blocked proteasome activity with MG132. This treatment prevented PMCA2-dependent loss of $\alpha 7$-nAChR clusters (Fig. 4A). The results suggest a homeostatic response to increases in calcium: PMCA2 inhibition allows intracellular calcium to increase, and the calcium elevation, acting through CaMKII, reduces the number of $\alpha 7$-nAChR clusters on the cell surface in a manner that depends on proteasome activity.

To identify the region of the $\alpha 7$-nAChR necessary for the PMCA2-dependent regulation, we used chimeras composed of nAChR fragments fused with the CD4 receptor (Xu et al., 2006; Fig. $4 B$ ). The second cytoplasmic loop of $\alpha 3$-containing nAChRs has previously been shown to be important for localizing such receptors on neurons (Williams et al., 1998). Accordingly, immunoprecipitation experiments were performed on extracts of transfected HEK293 cells expressing a chimera of the CD4 receptor fused with the second cytoplasmic loop of the $\alpha 7-\mathrm{nAChR}$ (CD4- $\alpha 7$ ). The $\alpha 7$-nAChR loop was sufficient for coimmunoprecipitation with PMCA2 (Fig. 4C). Substituting the equivalent region of the $\alpha 4-\mathrm{nAChR}$ subunit (CD4- $\alpha 4$ ) as a negative control did not permit coimmunoprecipitation with PMCA2.

To test whether the second intracellular loop was also sufficient for PMCA2-mediated loss of $\alpha 7$-nAChR surface clusters,

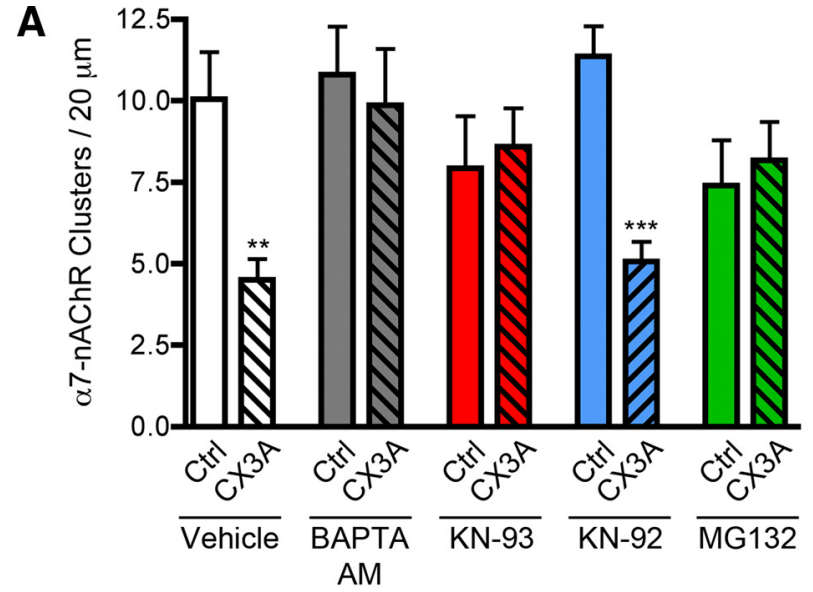

B

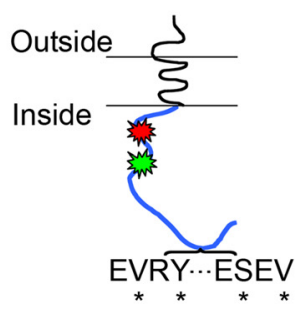

C

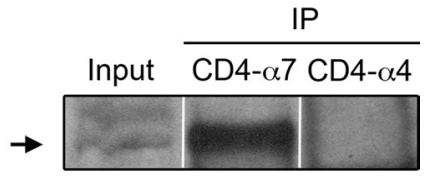

Blot: PMCA2 Ab

D
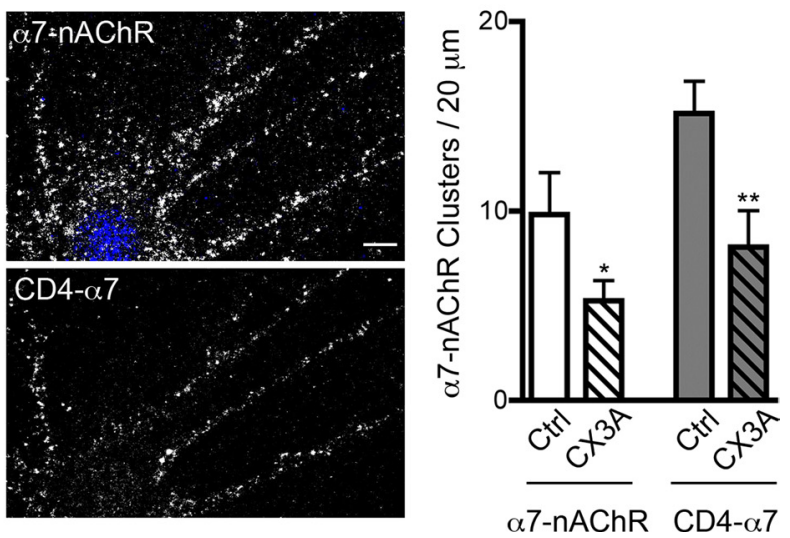

Figure 4. Molecular mechanisms mediating the PMCA2 effect on $\alpha 7$-nAChRs $A$, The reduction in receptor clusters depends on changes in intracellular calcium concentration [blocked by BAPTA-AM; vehicle (DMSO): $10 \pm 1.4$ and $4.5 \pm 0.6$ for control (ctrl) and CX3A, respectively; BAPTA-AM: $10.8 \pm 1.5$ and $9.8 \pm 1.7$ for control and CX3A respectively; ${ }^{* *} p=0.006$ by two-tailed $t$ test; $n=25$ interneurons] and on CaMKIl activity (blocked by KN93:7.9 \pm 1.6 and $8.6 \pm 1.2$ for control and $\mathrm{CX} 3 \mathrm{~A}$, respectively; $n=23$ interneurons; KN92 as negative control: $11.3 \pm 0.9$ and $5.06 \pm 0.6$ for control and $C X 3 A$, respectively; ${ }^{* *} p=0.0009$ by two-tailed $t$ test; $n=20$ interneurons). The reduction also depends on proteasomal activity (blocked by MG132: $7.4 \pm 1.4$ and $8.2 \pm 1.2$ for control and $(X 3 A$, respectively; $n=27$ interneurons). $\boldsymbol{B}$, Schematic representation of a chimeric receptor containing the CD4 receptor extracellular and transmembrane domains (black line) and the second cytoplasmic loop sequence of $\alpha 7$-nAChR subunits (blue line). Consensus sequences for PKC and CKII are indicated by red and green symbols, respectively. PDZ motifs are indicated by their amino acid sequences. Asterisks indicate the position of mutated residues. C, Coimmunoprecipitation of PMCA2-Myc and CD4 chimeras transiently transfected into HEK293 cells. Proteins were immunopurified (IP) with Abs against the extracellular region of the $C D 4$ sequence for both the $C D-\alpha 7$ and the $C D 4-\alpha 4$ receptors. Arrow indicates the PMCA2-Myc band. Similar results were obtained from three independent experiments. $\boldsymbol{D}$, Left, Representative images of surface endogenous $\alpha 7$-nAChRs or surface $C D 4-\alpha 7$ on the same hippocampal interneuron (blue). Right, $C X 3$ A treatment reduces both the number of endogenous $\alpha 7$-nAChR clusters and transfected CD4- $\alpha 7$ clusters $(\alpha 7$ nAChRs: $9.8 \pm 2.2$ and $5.3 \pm 1$ for control and $C X 3$ A, respectively; ${ }^{*} p=0.039$ by two-tailed $t$ test; $C D 4 \alpha 7$-loop: $15.1 \pm 1.7$ and $8.1 \pm 1.9$ for control and $C X 3$, respectively; ${ }^{* *} p=0.008$ by two-tailed $t$ test; $n=21-23$ transfected interneurons). 
we transfected hippocampal neurons in culture with the CD4- $\alpha 7$ loop (Fig. $4 D$ ) and inhibited PMCA2 activity. This resulted in loss of CD4- $\alpha 7$ loop clusters, as it did loss of endogenous $\alpha 7-\mathrm{nAChR}$ clusters (Fig. 4D). Candidate domains within the second intracellular loop of $\alpha 7$-nAChRs for mediating the PMCA2 effect include consensus motifs for protein kinase $\mathrm{C}$ (PKC), casein kinase II (CKII), and two type-1 PDZ domains (Fig. $4 B$ ). None of these appeared essential. Pharmacological blockade of either PKC with GF109203x or CKII with 4,5,6,7-tetrabromobenzotriazole (TBB) had no effect on either the control number of $\alpha 7$-nAChR clusters or the number remaining after PMCA2 inhibition [vehicle (DMSO): $10.2 \pm 1.7$ and $7 \pm 1.2$ for control and CX3A, respectively; GF109203x: $9.6 \pm 1.4$ and $4.5 \pm 0.8$ for control and CX3A, respectively; TBB: $9.1 \pm 1.3$ and $5.5 \pm 1$ for control and CX3A, respectively; $p<0.05$ for DMSO and TBB by two-tailed $t$ test; $p<0.01$ for GF109203x by two-tailed $t$ test; $n=18-25$ interneurons; data not shown]. Though the PDZ domains might be expected to mediate protein interactions, mutating both the second and fourth residues to alanine in either or both PDZ domains had no effect on the ability of the chimeric construct to associate with PMCA2 as indicated by immunoprecipitation (data not shown). The results demonstrate that the second cytoplasmic loop of $\alpha 7$-nAChRs is required for interaction with and regulation by PMCA2, but that the PMCA2 association does not depend on previously identified binding motifs present in the loop.

\section{Control of $\alpha 7-n A C h R$ lateral mobility by PSD-95}

Close proximity of PMCA2s and $\alpha 7$ nAChRs within membrane microdomains is likely to be critical for the regulation observed. Scaffold proteins represent candidates for mediating this proximity. They previously have been shown to be associated with other nAChRs (Temburni et al., 2004; Rosenberg et al., 2008), and PSD-95 specifically has been reported to interact both with PMCA2 in vivo (DeMarco and Strehler, 2001; Garside et al., 2009) and with $\alpha 7$-nAChRs in cell culture (Farías et al., 2007). Pursuing this possibility, we identified an interaction between PSD-95 and $\alpha 7-\mathrm{nAChR}$ in vivo by coimmunoprecipitation from rat brain extracts (Fig. $5 A$ ). In addition, immunostaining showed that $\alpha 7$-nAChRs in part colocalize both with PSD-95 and with PMCA2 on hippocampal interneurons in culture (Fig. 5B).

To detect changes in receptor location within a membrane microdomain, we used SPT with QDs attached to $\alpha 7$-nAChRs. This technique provides the high localization accuracy needed for detecting changes in $\alpha 7$-nAChR location in a small area of plasma

A

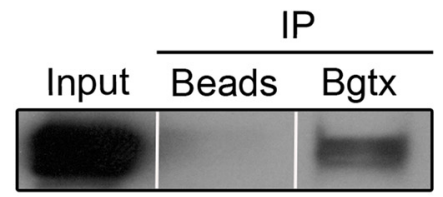

Blot: PSD-95 Ab
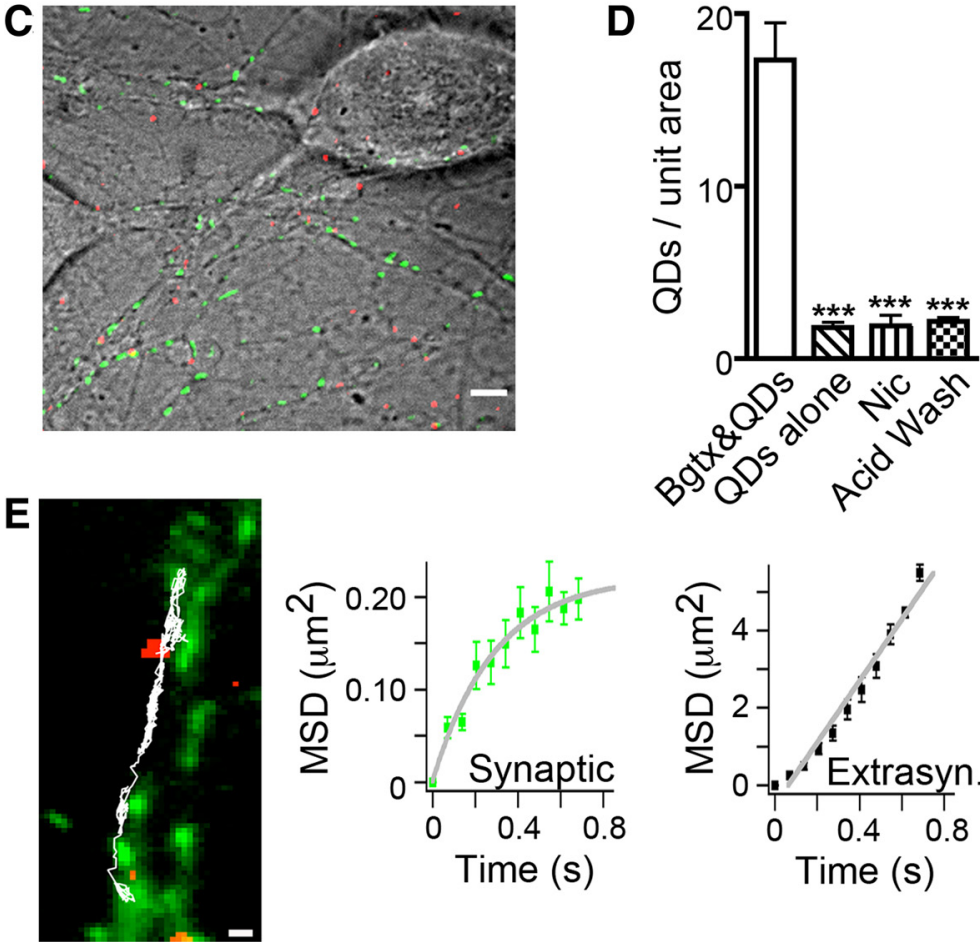

Figure 5. PSD-95 is associated with $\alpha 7-n A C h R s$, and the receptors are constrained in synaptic space on aspiny neurons. $\boldsymbol{A}$, Endogenous PSD-95 coaffinity purified with $\alpha 7-n A C h R s$ from rat brain extracts using the specific $\alpha 7-n A C h R$ agonist Bgtx attached to beads (Bgtx), and not by plain beads as a control (Beads). Equivalent results were obtained with six independent rat brain extracts. $\boldsymbol{B}$, Top, Colocalization (arrows indicate examples) of surface $\alpha 7-n A C h R s$ (green) and PSD-95 (red) on hippocampal erneurons (GAD65, blue; 15-17 d in vitro). Bottom, Colocalization of PMCA2 (green) and PSD-95 (red) under the same conditions. Scale bars: $2 \mu \mathrm{m}$. C, Representative image of surface endogenous QD- $\alpha 7-n A C h R$ complexes (red) on hippocampal neurons (bright field image). Synapses were labeled using Mitotracker (green). Scale bar: $5 \mu \mathrm{m}$. D, Number of QD- $\alpha$ 7-nAChR complexes on nicotine added with the Bgtx to block binding (Nic), and Bgtx plus QDs but acid-stripped afterward to remove QDs from surface receptors (Acid Wash). Bgtx\&QDs, $17.3 \pm 2.2 ;$ QDs alone, $1.8 \pm 0.3$; Nic. comp., $1.9 \pm 0.6$; Acid Wash, $2.2 \pm 0.2\left(^{* * *} p<0.001\right.$ (white) of a postsynaptic $\alpha 7-Q D$ complex (red) during a 1 min recording. Synaptic locations were identified by transfected SAP-102-GFP (green). Scale bar: $1 \mu \mathrm{m}$. Right, MSD plots versus time for synaptic and extrasynaptic $\alpha 7-Q D$ movement.

membrane over time (Triller and Choquet, 2008). In this way, we examined the possibility that PSD-95 controls $\alpha 7-n A C h R$ position by constraining receptor lateral mobility in the plasma membrane, functionally linking them to PMCA2s in microdomains. The QDs were specifically attached to $\alpha 7-\mathrm{nAChRs}$ by using a streptavidin-conjugate that recognizes Bgtx biotin bound to the receptors (Fig. 5C,D). After transfecting aspiny neurons with SAP-102-GFP to label synapses, individual $\alpha 7-n A C h R s-Q D$ complexes were tracked as they entered and exited synaptic space (Fig. 5E). MSD plots revealed that the receptor displayed random-walk diffusion in extrasynaptic space but became spatially constrained when in synapses (Fig. 5E). Quantification of 
A

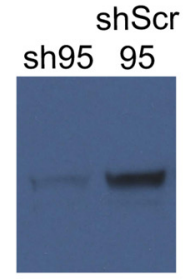

Blot: PSD-95 Ab

C
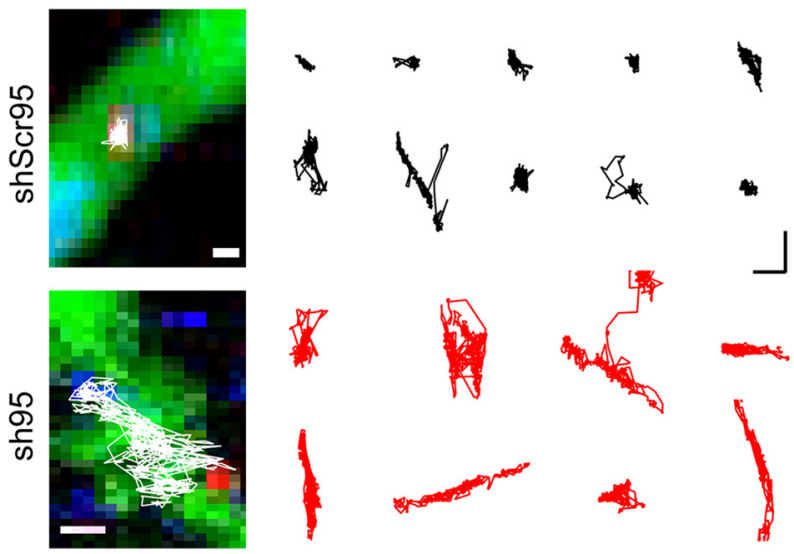

D
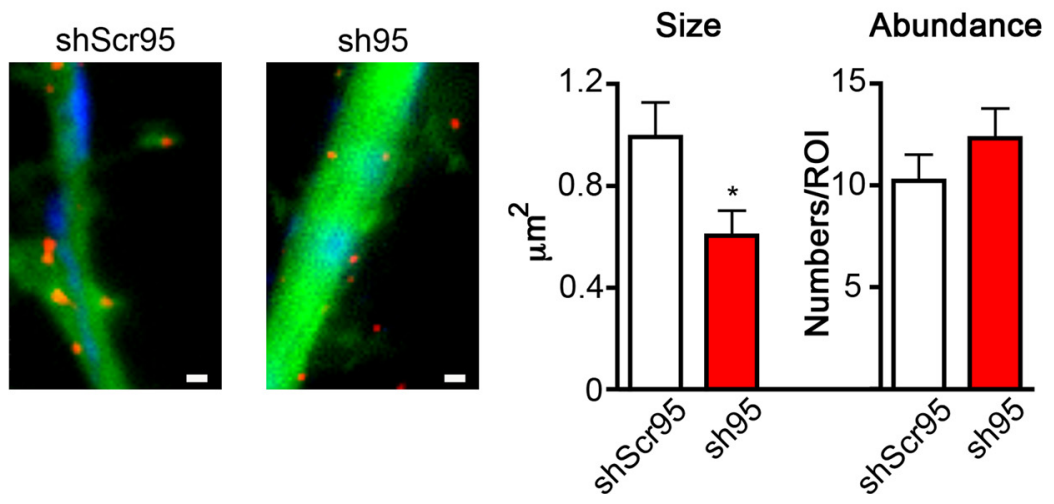

Figure 6. PSD-95 controls lateral mobility of $\alpha 7-n A C h R$. $\boldsymbol{A}$, Western blot of mouse PSD-95-GFP (dark band) transfected in HEK293 cells, together with sh95 or shScr95. B. Representative images of total endogenous PSD-95 (red) on hippocampal neurons transfected (green) with either shScr95 or sh95. Scale bar: $2 \mu \mathrm{m}$. C, Left, Tracings of the trajectories (white) of a postsynaptic $\alpha 7-Q D$ (red) on an aspiny neuron transfected with either shScr95 or sh95. Synapses are indicated by Mitotracker staining (blue). Scale bars: $1 \mu \mathrm{m}$. Right, Examples of $\alpha 7-Q D$ trajectories recorded on interneurons transfected either with shScr95 (black) or sh95 (red). Scale bars: $2 \mu \mathrm{m}$. Mean Feret's diameter values calculated for $\alpha 7-\mathrm{QD}$ complexes ( $2.1 \pm 0.3$ and $4.1 \pm 0.6 \mu \mathrm{m}$ for shScr95 and sh95, respectively; ${ }^{* *} p=0.009$ by two-tailed $t$ test; $n=15$ transfected interneurons from 3 cultures). D, PSD-95 knockdown reduces size of $\alpha 7$-nAChR clusters. Left, Representative images of surface $\alpha 7$-nAChRs (red) on interneurons (blue) transfected with either shScr95 or sh95 (green). Scale bars: $1 \mu \mathrm{m}$. Right, sh95 reduces surface $\alpha 7$-nAChR cluster size $(0.99 \pm 0.1$ and $0.6 \pm$ $0.1 \mu \mathrm{m}^{2}$ for shScr95 and sh95, respectively; ${ }^{*} p=0.03$ for two-tailed $t$ test; $n=12-16$ transfected interneurons) but not $\alpha 7$-nAChR cluster number (10.2 \pm 1.3 and $12.3 \pm 1.4$ for shScr95 and sh95, respectively; $n=12-16$ transfected interneurons; ROI for quantification: $20 \mu \mathrm{m}$ linear segment embedding the dendritic area).

diffusion coefficients demonstrated that receptor mobility was two times greater in extrasynaptic space than in synapses: 0.077 $\mu \mathrm{m}^{2} / \mathrm{s}$ (IQR [interquartile range], $0.04-0.098 \mu \mathrm{m}^{2} / \mathrm{s}$ ) and 0.165 $\mu \mathrm{m}^{2} / \mathrm{s}$ (IQR, $0.095-0.2 \mu \mathrm{m}^{2} / \mathrm{s}$ ) for synaptic and extrasynaptic space, respectively ( $n=54,60$ trajectories; three cultures; $p<$ 0.001 , by Mann-Whitney test).

To test the role of PSD-95 in constraining receptor mobility, we again used RNAi. Knockdown of PSD-95, using a specific construct (sh95, Fig. $6 A, B$ ), enabled $\alpha 7$-nAChRs to diffuse more extensively in aspiny neurons as reflected by their tracks (Fig.

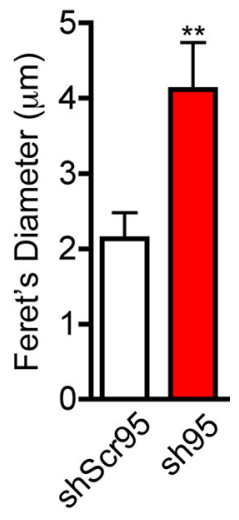

6C). Measuring the average distance between the two most distal points of the trajectory (Feret's diameter) indicated that $\alpha 7-\mathrm{nAChRs}$ on interneurons expressing sh95 moved twice as far on average as did $\alpha 7$-nAChRs on cells expressing the corresponding scrambled control shScr95 (Fig. 6C). Consistent with the changes observed in $\alpha 7$-nAChR mobility, we detected a reduced size of $\alpha 7-\mathrm{nAChR}$ clusters on the neuronal surface after PSD-95 knockdown and no change in the number of such clusters (Fig. 6D). PSD-95 knockdown by sh95 had no effect on the choline-induced calcium transients caused by $\alpha 7$-nAChRs, as expected (data not shown). The results identify PSD-95 as the first known protein to control the localization of $\alpha 7$-nAChRs on CNS neurons by means of limiting receptor mobility in the plasma membrane.

\section{Role of PSD-95 in mediating PMCA2 control of $\alpha 7-n A C h R s$}

An early indication that PSD-95 might be involved in the PMCA2 regulation of $\alpha 7$ nAChR clusters came from the observation that treating cultures with $\mathrm{CX} 3 \mathrm{~A}$ caused a decrease in the size of the largest quartile of PSD-95 puncta $(-17 \pm 0.02 \%$, $n=23$ interneurons; $p \leq 0.01$ ) found on hippocampal interneurons. No change was seen in the other quartiles, and no change was seen in the total number of PSD-95 puncta (data not shown). This suggested that PMCA2 blockade may cause the loss of a specific population of PSD-95 molecules and their associated proteins. Conversely, downregulation of PSD-95 by expression of sh95 decreased the mean size of PMCA2 puncta without changing the number of such puncta $(-41 \pm 7 \% ; n=18$ interneurons; $p \leq$ $0.01)$; this parallels the effect of sh95 on $\alpha 7$-nAChR clusters (see above).

To test directly whether PSD-95 is required for the loss of $\alpha 7-\mathrm{nAChR}$ clusters caused by PMCA2 inhibition, we examined hippocampal interneurons expressing sh95. Inhibition of PMCA2 with CX3A was unable to reduce the number of $\alpha 7-\mathrm{nAChR}$ clusters in this case (Fig. $7 A, B$ ). Importantly, PSD-95 knockdown did not alter the number of either $\alpha 7$-nAChR (Fig. 6B) or PMCA2 clusters (data not shown) under control conditions (i.e., in the absence of CX3A). These results demonstrate that PSD-95 is required for PMCA2mediated loss of $\alpha 7$-nAChR clusters, apparently by constraining receptor mobility and functionally linking them to PMCA2 and regulatory machinery in the cell (Fig. $7 C$ ).

\section{Discussion}

The results presented here demonstrate a new mechanism for controlling local calcium dynamics in neurons. The ion channel 
responsible for elevating intracellular calcium can be tightly coupled to a device capable of removing the calcium that enters and limits its spread. Further, the coupling can be used to target the ion channel for removal from the site if local calcium levels exceed a critical threshold. For $\alpha 7$ nAChRs on interneurons, the coupling is provided by PSD-95, which functionally links the receptors to PMCA2. If the calcium pump is unable to limit local calcium elevations, as in the case of pump inhibition, the cell quickly eliminates the $\alpha 7$-nAChR clusters. The regulation appears dedicated in that it does not extend either to GluR1-containing or NR1containing receptors on the same neurons; both types are calcium-permeable and reported to interact with PSD-95 and calcium pumps (Goldberg et al., 2003; Garside et al., 2009).

Previous studies showed that PMCA proteins participate in multiprotein calcium signaling complexes (Strehler et al., 2007). Several PMCA2 isoforms have been shown to interact with synapseassociated PDZ-contained proteins, including members of the PSD-95 family (DeMarco and Strehler, 2001). In rat cerebellum, postsynaptic PMCA2 interacts with NR1-containing and NR2-containing NMDA receptors (Garside et al., 2009). These findings suggest that PMCA2 localization may be used to promote calcium homeostasis in membrane microdomains containing calcium-permeable ligand-gated ion channels.

Functional proteomics has emerged as a powerful strategy for identifying proteins comprising molecular networks to regulate neuronal receptors (Schulte et al., 2011). Though large-scale screening of interactive proteins has recently been extended to nAChRs, functional interactions have yet to be identified this way (Kabbani et al., 2007; Paulo et al., 2009). Using an unbiased proteomic approach, we show here that $\alpha 7-n A C h R s$ are functionally tethered to PMCA2 and, together with PSD-95, the components form a functional unit that achieves two kinds of regulation. The first is an immediate constraint of calcium spread following $\alpha 7-\mathrm{nAChR}$ activation, reminiscent of that achieved by the interplay between calcium-permeable AMPA receptors and $\mathrm{a} \mathrm{Na}^{+} / \mathrm{Ca}^{2+}$ exchanger in neocortical fast-spiking interneurons to localize calcium in microdomains (Goldberg et al., 2003). The second, and more radical, is rapid loss of $\alpha 7-\mathrm{nAChR}$ clusters in response to PMCA2 blockade, suggesting a homeostatic mechanism for controlling calcium levels similar to that reported for AMPA receptor loss following $\mathrm{Na}^{+} / \mathrm{K}^{+}$-ATPase pump blockade on pyramidal neurons (Zhang et al., 2009).

Imaging techniques have been used to assess trafficking of nAChRs to the plasma membrane from interior locations (Nashmi et al., 2003; Richards et al., 2011). Recent studies using
SPT have shown that $\alpha 7$-nACRs are mobile on the neuron surface but display constraint in synaptic/perisynaptic domains (Bürli et al., 2010; Fernandes et al., 2010). The receptors interact with several scaffold proteins including PSD-93, PSD-95, PICK1 (protein interacting with $\mathrm{C}$ kinase-1), and APC (adenomatous polyposis coli) depending on location (Conroy et al., 2003; Baer et al., 2007; Farías et al., 2007). Axotomy-induced synaptic degeneration disperses postsynaptic PSD-93 before mobilizing $\alpha 7$ nACRs, consistent with a functional interaction (McCann et al., 2008). Recently, it has been shown that specific disruption of PDZ-containing scaffolds increases $\alpha 7$-nACR mobility on avian neurons (Fernandes et al., 2010). The SPT studies reported here identify PSD-95 as the first protein that constrains $\alpha 7-\mathrm{nACR}$ mobility on the neuron surface and functionally links the receptors to PMCA2. This link mediates regulation of $\alpha 7$-nACRs by PMCA2. 
To achieve the regulation seen, the PMCA2/ $\alpha 7-n A C h R$ complex must be positioned in microdomains where appropriate cellular machinery can eliminate $\alpha 7-n A C h R$ clusters in a calcium-dependent manner, as occurs when PMCA2 is inhibited. This requires participation of additional components, possibly also tethered to the complex. CaMKII may be one such a component. Activation of CaMKII can enhance receptor trafficking in the membrane and promote recycling (Derkach et al., 1999; Malinow and Malenka, 2002). Moreover, CaMKII can phosphorylate PSD-95, controlling the association between PSD-95 and NMDA2A receptors (Gardoni et al., 2006; Tsui and Malenka, 2006). We show here that CaMKII is required for loss of $\alpha 7$ $n A C h R$ clusters following PMCA2 inactivation, and may determine the local precision of the response. Only those domains experiencing elevated calcium will activate CaMKII, and only those activated complexes also positioned near appropriate cellular machinery will remove $\alpha 7$-nAChR clusters. Notably, calcium influx through $\alpha 7$-nAChRs themselves is not required because CX3A treatment induces cluster loss even when the receptors are prelabeled with Alexa488-Bgtx and methyllycaconitine is added, blocking their function (data not shown). Rather, it is PMCA2 inactivation that induces loss of associated $\alpha 7$-nAChR clusters in a calcium-dependent and CaMKIIdependent manner.

Loss of $\alpha 7$-nAChR clusters following PMCA2 inhibition depended on proteasomal degradation. Proteasomal activity has previously been shown to regulate the number and stability of nicotinic receptors (Rezvani et al., 2007; Govind et al., 2012). The loss of $\alpha 7$-nAChR clusters here may reflect either their internalization or dispersal on the cell surface. Current methods of immunodetection do not allow us to distinguish between extensive dispersal of clusters on the surface versus receptor internalization. We can detect small changes in cluster size, as in the case of sh95-treated neurons, and these produce no change in the choline-induced calcium response (data not shown). The large decrements in response caused by CX3A treatment, together with the substantial reduction in number of clusters, therefore suggests either complete (radical) dispersal or, more likely, receptor internalization. In either case, proteasomal dependency may also reflect a requirement for proteasomal degradation and turnover of regulatory components affecting $\alpha 7$-nAChR location on the surface. The proteasome has previously been shown to be essential for removal of calcium-permeable ion channels when a specific ion pump was inhibited (Zhang et al., 2009). PMCA2 is also known to be degraded by the proteasome when ATP production is compromised (Mbaya et al., 2010).

The physical association of PMCA2 with $\alpha 7-n A C h R s$ may identify the complex as a target for the proteasome when the pump is inhibited by CX3A. This physical association depends on the second intracellular loop of the $\alpha 7$-nAChR subunit but does not require any of the sequences identified as potential binding/ regulatory motifs. The loop likely connects the $\alpha 7-\mathrm{nAChR}$ to the PSD-95 scaffold, as has been suggested for the receptor link to PICK1 (Baer et al., 2007). The ability to coimmunoprecipitate PMCA2 with $\alpha 7$-nAChRs when both are expressed in transfected HEK cells may reflect the presence of an endogenous scaffold protein that can link the two. HEK cells express SAP-97, for example, a member of the PSD-95 family (Sabio et al., 2005).

Importantly, not all PMCA2/PSD-95 complexes with calcium-permeable receptors display the regulatory response to calcium elevations seen here for $\alpha 7$-nAChRs. As noted above, neither GluR1-containing AMPA receptor clusters nor NMDA receptor clusters containing NR1 receptors were dispersed by
PMCA2 blockade though both classes of receptors have been shown previously to interact with PSD-95, and at least NMRA receptors have been shown to be associated with PMCA2 (Garside et al., 2009). Notably, CX3A blockade of PMCA2 decreased the size of the largest PSD-95 puncta without changing the total number of PSD-95 puncta. Individual microdomains of such puncta presumably reflect unique regulatory units, depending on the components and receptors attached.

It may seem paradoxical that knockdown of PMCA2 by RNAi did not produce loss of $\alpha 7$-nAChR clusters, in contrast to the effects PMCA2 blockade by CX3A. PMCA2 knockdown, however, is usually less than complete and requires multiple days; this could induce compensatory changes, perhaps increasing other PMCAs known to be in hippocampal neurons (Marcos et al., 2009). PMCA knockdown, for example, was shown recently to increase calmodulin levels (Boczek et al., 2012), relevant here because CaMKII mediates the $\alpha 7$-nAChR loss observed. An interesting alternative is that the physical presence of PMCA2, as noted above, may be needed as part of the signaling complex triggering loss of $\alpha 7$-nAChR clusters when intracellular calcium levels increase.

Previous work has shown that $\alpha 7$-nAChRs can also occupy presynaptic positions at a variety of locations (McGehee et al., 1995; Gray et al., 1996; Alkondon and Albuquerque, 2001; Sharma and Vijayaraghavan, 2003), as does PMCA2 (Garside et al., 2009). Here we focused on postsynaptic $\alpha 7-n A C h R s$ and their interactions with PMCA2. The role of presynaptic $\alpha 7-n A C h R s$, however, and their dependence on calcium to influence transmitter release raises obvious questions about possible $\alpha 7$-nAChRs/ PMCA2 interactions similar to those identified here on the postsynaptic side. This will be important to address when imaging techniques are available to visualize presynaptic $\alpha 7-n A C h R s$.

The calcium regulatory mechanisms identified here may be particularly important in cellular domains where physical compartmentalization is difficult, as in the case of dendritic shafts on aspiny interneurons. Though interneurons were originally thought only to regulate the flow of excitability generated by pyramidal neurons, it is now clear that the cells display multiple forms of plasticity, some of which are pathway-specific (Kullmann and Lamsa, 2007). The mechanisms required for constraining calcium fluctuations to microdomains remain largely unexplored (Kullmann and Lamsa, 2007; Michaelsen and Lohmann, 2010). Regulation of calcium dynamics by the orchestrated activity of specific protein complexes, like the one shown here, offers an additional possibility. Future interactomics studies on other neuronal receptors will help determine whether the principles identified here are fundamental to the regulation of calcium dynamics where physical compartmentalization is not available.

\section{References}

Albuquerque EX, Pereira EF, Alkondon M, Rogers SW (2009) Mammalian nicotinic acetylcholine receptors: from structure to function. Physiol Rev 89:73-120.

Alkondon M, Albuquerque EX (2001) Nicotinic acetylcholine receptors $\alpha 7$ and $\alpha 4 \beta 2$ subtypes differentially control GABAergic input to CA1 neurons in rat hippocampus. J Neurophysiol 86:3043-3055.

Aravanis AM, Pyle JL, Tsien RW (2003) Single synaptic vesicles fusing transiently and successively without loss of identity. Nature 423:643-647.

Baer K, Bürli T, Huh KH, Wiesner A, Erb-Vögtli S, Göckeritz-Dujmovic D, Moransard M, Nishimune A, Rees MI, Henley JM, Fritschy JM, Fuhrer C (2007) PICK1 interacts with alpha7 neuronal nicotinic acetylcholine receptors and controls their clustering. Mol Cell Neurosci 35:339-355.

Bertrand D, Galzi JL, Devillers-Thiéry A, Bertrand S, Changeux JP (1993) Mutations at two distinct sites within the channel domain M2 alter cal- 
cium permeability of neuronal alpha 7 nicotinic receptor. Proc Natl Acad Sci U S A 90:6971-6975.

Boczek T, Kozaczuk A, Ferenc B, Kosiorek M, Pikula S, Zylinska L (2012) Gene expression pattern in PC12 cells with reduced PMCA2 or PMCA3 isoform: selective up-regulation of calmodulin and neuromodulin. Mol Cell Biochem 360:89-102.

Bürli T, Baer K, Ewers H, Sidler C, Fuhrer C, Fritschy JM (2010) Single particle tracking of alpha7 nicotinic AChR in hippocampal neurons reveals regulated confinement at glutamatergic and GABAergic perisynaptic sites. PLoS One 5:e11507.

Charrier C, Ehrensperger MV, Dahan M, Lévi S, Triller A (2006) Cytoskeleton regulation of glycine receptor number at synapses and diffusion in the plasma membrane. J Neurosci 26:8502-8511.

Conroy WG, Liu Z, Nai Q, Coggan JS, Berg DK (2003) PDZ-containing proteins provide a functional postsynaptic scaffold for nicotinic receptors in neurons. Neuron 38:759-771.

Dajas-Bailador F, Wonnacott S (2004) Nicotinic acetylcholine receptors and the regulation of neuronal signalling. TIPS 25:317-324.

DeMarco SJ, Strehler EE (2001) Plasma membrane $\mathrm{Ca}^{2+}$-atpase isoforms $2 \mathrm{~b}$ and $4 \mathrm{~b}$ interact promiscuously and selectively with members of the membrane-associated guanylate kinase family of PDZ (PSD95/Dlg/ ZO-1) domain-containing proteins. J Biol Chem 276:21594-21600.

Derkach V, Barria A, Soderling TR (1999) $\mathrm{Ca}^{2+} /$ calmodulin-kinase II enhances channel conductance of alpha-amino-3-hydroxy-5-methyl-4isoxazolepropionate type glutamate receptors. Proc Natl Acad Sci U S A 96:3269-3274.

Descarries L, Gisiger V, Steriade M (1997) Diffuse transmission by acetylcholine in the CNS. Prog Neurobiol 53:603-625.

Dickinson JA, Hanrott KE, Mok MH, Kew JN, Wonnacott S (2007) Differential coupling of $\alpha 7$ and non $\alpha 7$ nicotinic acetylcholine receptors to calcium-induced calcium release and voltage-operated calcium channels in PC12 cells. J Neurochem 100:1089-1096.

Dingledine R, Borges K, Bowie D, Traynelis SF (1999) The glutamate receptor ion channels. Pharmacol Rev 51:7-61.

Ehlers MD, Heine M, Groc L, Lee MC, Choquet D (2007) Diffusional trapping of GluR1 AMPA receptors by input-specific synaptic activity. Neuron 54:447-460.

Farías GG, Vallés AS, Colombres M, Godoy JA, Toledo EM, Lukas RJ, Barrantes FJ, Inestrosa NC (2007) Wnt-7a induces presynaptic colocalization of alpha 7-nicotinic acetylcholine receptors and adenomatous polyposis coli in hippocampal neurons. J Neurosci 27:5313-5325.

Fayuk D, Yakel JL (2007) Dendritic $\mathrm{Ca}^{2+}$ signalling due to activation of alpha 7-containing nicotinic acetylcholine receptors in rat hippocampal neurons. J Physiol 582:597-611.

Fernandes CC, Berg DK, Gómez-Varela D (2010) Lateral mobility of nicotinic acetylcholine receptors on neurons is determined by receptor composition, local domain, and cell type. J Neurosci 30:8841-8851.

Gardoni F, Polli F, Cattabeni F, Di Luca M (2006) Calcium-calmodulindependent protein kinase II phosphorylation modulates PSD-95 binding to NMDA receptors. Eur J Neurosci 24:2694-2704.

Garside ML, Turner PR, Austen B, Strehler EE, Beesley PW, Empson RM (2009) Molecular interactions of the plasma membrane calcium ATPase 2 at pre- and post-synaptic sites in rat cerebellum. Neuroscience 162:383-395.

Gatto C, Hale CC, Xu W, Milanick MA (1995) Eosin, a potent inhibitor of the plasma membrane Ca pump, does not inhibit the cardiac Na-Ca exchanger. Biochemistry 34:965-972.

Goetze B, Grunewald B, Baldassa S, Kiebler M (2004) Chemically controlled formation of a DNA/calcium phosphate coprecipitate: application for transfection of mature hippocampal neurons. J Neurobiol 60:517-525.

Goldberg JH, Tamas G, Aronov D, Yuste R (2003) Calcium microdomains in aspiny dendrites. Neuron 40:807-821.

Gómez-Varela D, Kohl T, Schmidt M, Rubio ME, Kawabe H, Nehring RB, Schäfer S, Stühmer W, Pardo LA (2010) Characterization of Eagl channel lateral mobility in rat hippocampal cultures by single-particletracking with quantum dots. PLoS One 5:e8858.

Govind AP, Walsh H, Green WN (2012) Nicotine-induced upregulation of native neuronal nicotinic receptors is caused by multiple mechanisms. J Neurosci 32:2227-2238.

Gray R, Rajan AS, Radcliffe KA, Yakehiro M, Dani JA (1996) Hippocampal synaptic transmission enhanced by low concentrations of nicotine. Nature 383:713-716.
Jensen TP, Filoteo AG, Knopfel T, Empson RM (2007) Presynaptic plasma membrane $\mathrm{Ca} 2+$ ATPase isoform 2a regulates excitatory synaptic transmission in rat hippocampal CA3. J Physiol 579:85-99.

Jones S, Sudweeks S, Yakel JL (1999) Nictinic receptors in the brain: correlating physiology with function. Trends Neurosci 22:555-561.

Kabbani N, Woll MP, Levenson R, Lindstrom JM, Changeux JP (2007) Intracellular complexes of the beta2 subunit of the nicotinic acetylcholine receptor in brain identified by proteomics. Proc Natl Acad Sci U S A 104:20570-20575.

Kaeser PS, Deng L, Wang Y, Dulubova I, Liu X, Rizo J, Südhof TC (2011) RIM proteins tether $\mathrm{Ca} 2+$ channels to presynaptic active zones via a direct PDZ-domain interaction. Cell 144:282-295.

Kawai H, Zago W, Berg DK (2002) Nicotinic alpha 7 receptor clusters on hippocampal GABAergic neurons: regulation by synaptic activity and neurotrophins. J Neurosci 22:7903-7912.

Keller A, Nesvizhskii AI, Kolker E, Aebersold R (2002) Empirical statistical model to estimate the accuracy of peptide identifications made by MS/MS and database search. Anal Chem 74:5383-5392.

Khiroug L, Giniatullin R, Klein RC, Fayuk D, Yakel JL (2003) Functional mapping and $\mathrm{Ca}^{2+}$ regulation of nicotinic acetylcholine receptor channels in rat hippocampal CA1 neurons. J Neurosci 23:9024-9031.

Kozel PJ, Friedman RA, Erway LC, Yamoah EN, Liu LH, Riddle T, Duffy JJ, Doetschman T, Miller ML, Cardell EL, Shull GE (1998) Balance and hearing deficits in mice with a null mutation in the gene encoding plasma membrane Ca2+-ATPase isoform 2. J Biol Chem 273:18693-18696.

Kullmann DM, Lamsa KP (2007) Long-term synaptic plasticity in hippocampal interneurons. Nat Rev Neurosci 8:687-699.

Malinow R, Malenka RC (2002) AMPA receptor trafficking and synaptic plasticity. Annu Rev Neurosci 25:103-126.

Marcos D, Sepulveda MR, Berrocal M, Mata AM (2009) Ontogeny of ATP hydrolysis and isoform expression of the plasma membrane $\mathrm{Ca}^{2+}$ ATPase in mouse brain. BMC Neurosci 10:112.

Mbaya E, Oulès B, Caspersen C, Tacine R, Massinet H, Pennuto M, Chrétien D, Munnich A, Rötig A, Rizzuto R, Rutter GA, Paterlini-Bréchot P, Chami M (2010) Calcium signalling-dependent mitochondrial dysfunction and bioenergetics regulation in respiratory chain Complex II deficiency. Cell Death Differ 17:1855-1866.

McCann CM, Tapia JC, Kim H, Coggan JS, Lichtman JW (2008) Rapid and midifiable neurotransmitter receptor dynamics at a neuronal synapse in vivo. Nat Neurosci 11:807-815.

McGehee DS, Heath MJ, Gelber S, Devay P, Role LW (1995) Nicotine enhancement of fast excitatory synaptic transmission in CNS by presynaptic receptors. Science 269:1692-1696.

Michaelsen K, Lohmann C (2010) Calcium dynamics at developing synapses: mechanisms and functions. Eur J Neurosci 32:218-223.

Miwa JM, Freedman R, Lester HA (2011) Neural systems governed by nicotinic acetylcholine receptors: emerging hypotheses. Neuron 70:20-33.

Nashmi R, Dickinson ME, McKinney S, Jareb M, Labarca C, Fraser SE, Lester HA (2003) Assembly of $\alpha 4 \beta 2$ nicotinic acetylcholine receptors assessed with functional fluorescently labeled subunits: effects of localization, trafficking, and nicotine-induced upregulation in clonal mammalian cells and in cultured midbrain neurons. J Neurosci 23:11554-11567.

Neff RA 3rd, Conroy WG, Schoellerman JD, Berg DK (2009) Synchronous and asynchronous transmitter release at nicotinic synapses are differentially regulated by postsynaptic PSD-95 proteins. J Neurosci 29:15770-15779.

Nesvizhskii AI, Keller A, Kolker E, Aebersold R (2003) A statistical model for identifying proteins by tandem mass spectrometry. Anal Chem 75:4646-4658.

Pande J, Mallhi KK, Grover AK (2005) Role of third extracellular domain of plasma membrane $\mathrm{Ca} 2+-\mathrm{Mg} 2+-\mathrm{ATPa} e$ based on the novel inhibitor caloxin 3A1. Cell Calcium 37:245-250.

Paulo JA, Brucker WJ, Hawrot E (2009) Proteomic analysis of an alpha7 nicotinic acetylcholine receptor interactome. J Proteome Res 8:1849-1858.

Rezvani K, Teng Y, Shim D, De Biasi M (2007) Nicotine regulates multiple synaptic proteins by inhibiting proteasomal activity. J Neurosci 27:10508-10519.

Richards CI, Srinivasan R, Xiao C, Mackey ED, Miwa JM, Lester HA (2011) Trafficking of $\alpha 4^{\star}$ nicotinic receptors revealed by superecliptic phluorin. Effects of a $\beta 4$ amyotrophic lateral sclerosis-associated mutation and chronic exposure to nicotine. J Biol Chem 286:31241-31249. 
Rosenberg MM, Yang F, Giovanni M, Mohn JL, Temburni MK, Jacob MH (2008) Adenomatous polyposis coli plays a key role, in vivo, in coordinating assembly of the neuronal nicotinic postsynaptic complex. Mol Cell Neurosci 38:138-152.

Rózsa B, Katona G, Kaszás A, Szipöcs R, Vizi ES (2008) Dendritic nicotinic receptors modulate backpropagating action potentials and long-term plasticity of interneurons. Eur J Neurosci 27:364-377.

Sabio G, Arthur JS, Kuma Y, Peggie M, Carr J, Murray-Tait V, Centeno F, Goedert M, Morrice NA, Cuenda A (2005) p38gamma regulates the localisation of SAP97 in the cytoskeleton by modulating its interaction with GKAP. EMBO J 24:1134-1145.

Sage D, Neumann FR, Hediger F, Gasser SM, Unser M (2005) Automatic tracking of individual fluorescence particles: application to the study of chromosome dynamics. IEEE Trans Image Process 14:1372-1383.

Schiller J, Schiller Y, Clapham DE (1998) NMDA receptors amplify calcium influx into dendritic spines during associative pre- and postsynaptic activation. Nat Neurosci 1:114-118.

Schulte U, Müller CS, Fakler B (2011) Ion channels and their molecular environments-glimpses and insights from functional proteomics. Semin Cell Dev Biol 22:132-144.

Séguéla P, Wadiche J, Dineley-Miller K, Dani JA, Patrick JW (1993) Molecular cloning, functional properties, and distribution of rat brain $\alpha_{7}$ : a nicotinic cation channel highly permeable to calcium. J Neurosci 13:596-604

Sharma G, Vijayaraghavan S (2003) Modulation of presynaptic store calcium induces release of glutamate and postsynaptic firing. Neuron 38:929-939.

Strehler EE, Zacharias DA (2001) Role of alternative splicing in generating isoform diversity among plasma membrane calcium pumps. Physiol Rev 81:21-50.
Strehler EE, Filoteo AG, Penniston JT, Caride AJ (2007) Plasma-membrane $\mathrm{Ca}(2+)$ pumps: structural diversity as the basis for functional versatility. Biochem Soc Trans 35:919-922.

Temburni MK, Rosenberg MM, Pathak N, McConnell R, Jacob MH (2004) Neuronal nicotinic synapse assembly requires the adenomatous polyposis coli tumor suppressor protein. J Neurosci 24:6776-6784.

Triller A, Choquet D (2008) New concepts in synaptic biology derived from single-molecule imaging. Neuron 59:359-374.

Tsui J, Malenka RC (2006) Substrate localization creates specificity in calcium/calmodulin-dependent protein kinase II signaling at synapses. J Biol Chem 281:13794-13804.

Williams BM, Temburni MK, Levey MS, Bertrand S, Bertrand D, Jacob MH (1998) The long internal loop of the $\alpha 3$ subunit targets nAChRs to subdomains within individual synapses on neurons in vivo. Nat Neurosci $1: 557-562$.

Xu J, Zhu Y, Heinemann SF (2006) Identification of sequence motifs that target neuronal nicotinic receptors to dendrites and axons. J Neurosci 26:9780-9793.

Yuste R (2011) Dendritic spines and distributed circuits. Neuron 71:772-781.

Yuste R, Majewska A, Cash SS, Denk W (1999) Mechanisms of calcium influx into hippocampal spines: heterogeneity among spines, coincidence detection by NMDA receptors, and optical quantal analysis. J Neurosci 19:1976-1987.

Zago WM, Massey KA, Berg DK (2006) Nicotinic activity stabilizes convergence of nicotinic and GABAergic synapses on filopodia of hippocampal interneurons. Mol Cell Neurosci 31:549-559.

Zhang D, Hou Q, Wang M, Lin A, Jarzylo L, Navis A, Raissi A, Liu F, Man HY (2009) $\mathrm{Na}, \mathrm{K}$-ATPase activity regulates AMPA receptor turnover through proteasome-mediated proteolysis. J Neurosci 29:4498-4511. 